\title{
The effect of Bacillus coagulans on cytotoxicity and apoptosis induced by Salmonella Typhimurium in HT-29 cell culture
}

\author{
Amin Kawarizadeh ${ }^{1}$, Farshad Nojoomi ${ }^{{ }^{*}}$, Mohammad Tabatabaei ${ }^{2}$, Saeid Hosseinzadeh ${ }^{3}$, \\ Mina Farzaneh ${ }^{2}$ \\ ${ }^{l}$ Department of Microbiology, Faculty of Medicine, Aja University of Medical Sciences, Tehran, Iran \\ ${ }^{2}$ Department of Pathobiology, Faculty of Veterinary Medicine, Shiraz University, Shiraz, Iran \\ ${ }^{3}$ Department of Food Hygiene and Public Health, Faculty of Veterinary Medicine, Shiraz University, Shiraz, \\ Iran
}

Received: July 2018, Accepted: February 2019

\begin{abstract}
Background and Objectives: Human epithelial cells have been widely used to study the interaction between intestinal cells and pathogens, in vitro. In this study, the effect of probiotic bacteria Bacillus coagulans and its supernatant on the growth inhibition, cytotoxicity and induction of apoptosis caused by Salmonella Typhimurium and its adhesion to HT-29 cells were investigated.

Materials and Methods: B. coagulans supernatant was used to obtain the minimum inhibitory concentration. To evaluate the cytotoxicity and percent of apoptotic cells, B. coagulans and its supernatant (2, 4, 6 and $8 \%$ concentrations) with $S$. Typhimurium was added to HT-29 cells. The MTT assay was used in order to evaluate the cytotoxicity. Percent of apoptotic cells was reported using a fluorescence staining method. Additionally, the adhesion of $S$. Typhimurium to HT-29 cells was investigated. The effect of $B$. coagulans on the level of adhesion was also studied.

Results: The most inhibitory effect was shown at the concentration of $80000 \mu \mathrm{g} / \mathrm{ml}$ supernatant of B. coagulans $(54.77 \%$ \pm 1.43 ). The simultaneous culture of $S$. Typhimurium with $B$. coagulans had the lowest amount of cytotoxicity and induced apoptosis among the all co-culture groups of $S$. Typhimurium with $B$. coagulans or its supernatant. The determined cytotoxicity and induced apoptosis were $26.06 \% \pm 3.79$ and $17.63 \% \pm 2.14$ respectively. In the adhesion test, it was observed that B. coagulans can significantly prevent adhesion of $S$. Typhimurium to HT-29 cell.

Conclusion: B. coagulans can reduce the adhesion, cytotoxicity and induction of apoptosis caused by $S$. Typhimurium in HT-29 cells in vitro.
\end{abstract}

Keywords: Probiotics; Bacillus coagulans; Fluorescence staining; Minimum inhibitory concentration; Salmonella Typhimurium

"Corresponding author: Farshad Nojoomi, Ph.D, Department of Microbiology, Faculty of Medicine, Aja University of Medical Sciences, Tehran, Iran.
Tel: +98-21-2143822157

Fax: +98-21-2143822157

Email: fnojoomi@ajaums.ac.ir 


\section{INTRODUCTION}

According to the World Health Organization and FAO, probiotics are live microorganisms that have health benefits to the consumers, if consumed adequately (1). There is a strong tendency to use probiotic bacteria to treat and prevent various digestive disorders. Probiotics can inhibit the growth and invasion of pathogenic bacteria by strengthening the intestinal barrier and modulating the immune response by regulating the production of cytokines $(2,3)$. In addition probiotics can improve the intestinal microbial balance.

As such, microbial communities in the intestine or gut microbiome have a significant impact on the health of the host $(4,5)$. Human microbiome, especially intestinal microbiota, have a great impact on general health concerns and normal activities (6).

B. coagulans as a spore forming bacterium is one of the most promising probiotic bacteria, but still some of its pharmacological aspects have not been clarified yet (7). This bacterium can tolerate the acidic conditions of the stomach until it reaches the intestine and germinates there. It helps digest carbohydrates and proteins when it activates after germination in the gut (8). Consumption of B. coagulans makes the intestinal environment unfavorable for various pathogens and allows the use of nutrients by the intestinal system (9). In addition, studies have shown that B. coagulans $\mathrm{I} 4$, which is isolated from the cattle faeces, has antimicrobial activity with the production of bacteriocin-like inhibitors, called coagulin (10).

The usage of probiotics for the prevention and treatment of food poisoning has been considered. Clostridium botulinum, Clostridium perfringens, Escherichia coli, Staphylococcus aureus and S. Typhimurium are the major bacteria that cause foodborne illness (11).

In this research, $S$. Typhimurium has been studied. The genus Salmonella belongs to the Enterobacteriaceae family (12). This genus is composed of two species of Salmonella enterica and Salmonella bongori, a species of Salmonella enterica, containing more than 2000 different serovars. Some of these serovars, such as Salmonella Typhi, cause systemic infections and typhoid fever, and others, S. Typhimurium, cause gastroenteritis (13).

$S$. Typhimurium is an important food pathogen for both humans and animals (14). This organism has been associated with a wide spectrum of food contamination. S. Typhimurium, unlike $S$. Typhi, can also cause infection in many other mammalian species. Domestic animals can be used as a reservoir for the prevalence of this foodborne pathogen. This leads to a high incidence of non-typhoid Salmonella infection worldwide (13). Salmonella is capable of adhesion to host cells and invade and survive in the intestinal epithelial cells (15).

In vitro study on cell culture is an effective method for understanding the interaction between pathogenic bacteria and probiotics. This study was conducted to evaluate the antibacterial effects of B. coagulans on $S$. Typhimurium. For this purpose, the effect of B. coagulans and its supernatant on cell cytotoxicity and induced apoptosis by $S$. Typhimurium on the HT-29 cells was investigated using MTT and fluorescence staining. In addition, the minimum inhibitory concentration (MIC) of $B$. coagulans supernatant on this pathogen was also observed. The effect of $B$. coagulans and its supernatant on $S$. Typhimurium adhesion to HT-29 cells were evaluated.

\section{MATERIALS AND METHODS}

Bacterial preparation. Salmonella enterica Serovar Typhimurium ( $S$. Typhimurium) ATCC14028 was provided by the Department of Food Hygiene and Public Health, School of Veterinary Medicine, Shiraz University, Iran. S. Typhimurium was cultured in Tryptic Soy Broth (TSB) (Merck, Germany) and incubated for 24 hours at $37^{\circ} \mathrm{C}$. The cell suspension was used to carry out strike culture on blood agar medium and was re-incubated similarly for overnight. Single colonies were used in subsequent tests.

Cultivation of $B$. coagulans and preparation of its supernatant. Frozen B. coagulans GBI-30 was provided by Department of Food Hygiene and Public Health, School of Veterinary Medicine, Shiraz University, Iran. The cells were cultured in TSB medium and incubated for 24 hours at $37^{\circ} \mathrm{C}$. The cell suspension was then sub-cultured on the blood agar medium. Single colonies were used in subsequent tests. To obtain the supernatant from this bacterium, a colony was transferred to $10 \mathrm{ml}$ of TSB and incubated for 24 hours at $37^{\circ} \mathrm{C}$. The cell suspension was then transferred to $1000 \mathrm{ml}$ of sterile TSB and re-incubated for 
24 hours at $37^{\circ} \mathrm{C}$. The cell suspension was centrifuged at $4000 \mathrm{rpm}$ for 10 minutes. The supernatant was removed and dried by a freeze dryer machine. The supernatant deposition was prepared at concentrations of 1, 2, 4, 6 and $8 \%$ in RPMI 1640 medium and in $8 \%$ concentration in TSB medium. And finally filtered by 0.22 micrometer filter (16).

Measurement of MIC. Broth dilution method was used to measure MIC. For this purpose, 96-well microtitration plate (microdilution) was used. The $8 \%(80000 \mu \mathrm{g} / \mathrm{ml})$ supernatant in TSB medium in a volume of $100 \mu \mathrm{l} /$ well and $4 \%, 2 \%$ and $1 \%$ concentration were prepared by serial dilution. Then, each well was inoculated with $10 \mu$ l of bacterial suspension $\left(10^{7} \mathrm{CFU} / \mathrm{ml}\right)$. The TSB medium containing $S$. Typhimurium was considered as positive control and B. coagulans supernatant as negative control (17). Optical density of each well was measured at a wavelength of $600 \mathrm{~nm}$ at zero and after 24 hours after incubation at $37^{\circ} \mathrm{C}$. The experiment was done in triplicate (18). The percentage of growth inhibition was calculated using the following equation (19):

growth inhibition $=\frac{O-E}{O} \times 100$

Where O means OD of positive control at hour $24-$ $\mathrm{OD}$ at zero and $\mathrm{E}$ means $\mathrm{OD}$ of sample containing extract and bacterium at hour $24-\mathrm{OD}$ at zero

HT-29 cell culture. HT-29 cell line (Human colon adenocarcinoma) was provided by the Cancer Research Center, Shiraz University of Medical Sciences. HT-29 cells were cultured in $75 \mathrm{~cm}^{2}$ culture flask using RPMI 1640 medium with GlutaMax® (shell Max, Iran), $10 \%$ of heat-inactivated fetal bovine serum (Gibco Inc., America), $1 \%$ penicillin-streptomycin (10000 IU/ml and $10000 \mu \mathrm{g} / \mathrm{ml}$ ) (Bio-idea Inc., Iran). The flasks were incubated in a humified incubator with $5 \% \mathrm{CO}_{2}$ atmosphere at $37^{\circ} \mathrm{C}$. Culture medium was replaced by fresh medium every 2 days (15).

Preparation of cells for staining. HT-29 cells were seeded into $12.5 \mathrm{~cm}^{2}$ flask at a density of $5 \times 10^{5}$ cells /flask. The cells were incubated for 48 hours at $37^{\circ} \mathrm{C}$ under $5 \% \mathrm{CO}_{2}$ atmosphere to reach the confluency of $90 \%$. Then cultured B. coagulans and $S$. Typhimurium were centrifuged and the bacterial depo- sition was suspended in RPMI 1640 containing $2 \%$ fetal bovine serum. HT-29 cells were co-incubated with $2 \mathrm{ml}$ of $B$. coagulans $\left(10^{7} \mathrm{CFU} / \mathrm{ml} \mathrm{RPMI}\right)$ plus $S$. Typhimurium (10 $\mathrm{CFU} / \mathrm{ml} \mathrm{RPMI})$, as well as $2 \mathrm{ml}$ of each of 2, 4, 6 and $8 \%$ probiotic supernatant plus $S$. Typhimurium. The un-treated monolayer cells were considered as the negative control and the flask containing one layer of cells treated by $S$. Typhimurium was employed as the positive control. After 2 hours incubation, the supernatant was removed and then a cell washing with sterile PBS solution was done at $37^{\circ} \mathrm{C}$. In order to harvest the cells from the $12.5 \mathrm{~cm}^{2}$ flask, $300 \mu \mathrm{l}$ of filtered EDTA $(1 \mathrm{mM})$ was used. The cells were collected via centrifugation and suspended in $1 \mathrm{ml}$ of fresh RPMI 1640 medium.

Evaluation of apoptosis by acridine orange and ethidium bromide staining. Staining method was performed using the mixture of $1 \mu$ of acridine orange $(5 \mathrm{mg} / \mathrm{ml}), 1 \mu \mathrm{l}$ of ethidium bromide $(3 \mathrm{mg} / \mathrm{ml})$ dissolved in $1 \mathrm{ml}$ of phosphate buffer solution (PBS). Then $20 \mu \mathrm{l}$ of cell suspension was added to $5 \mu \mathrm{l}$ of the dye solution. $10 \mu 1$ of the dye-cell suspension was then placed on a hemocytometer and examined under a fluorescence microscope. Each sample was mixed just prior to microscopy and quantification. Acridine orange is a vital dye and stains both live and dead cells. Ethidium bromide stains only the cells that have lost membrane integrity. Live cells appeared uniformly green. Necrotic cells stained orange with no condensed chromatin. Apoptotic cells regarding be at the early or late stage of apoptosis, appeared green containing bright dots in nuclei or orange containing condensed nuclei, respectively. Experiment was performed in triplicates (20).

Evaluation of cytotoxicity. HT-29 cells were seeded in a 96-well flat bottom microtiter plate at a density of $10^{4}$ cells/well and incubated at $37^{\circ} \mathrm{C}$ in a CQ incubator. The culture medium was replaced daily with $100 \mu \mathrm{l}$ fresh RPMI 1640 medium containing $10 \%$ fetal bovine serum to reach a degree of confluency (about 90\%.). $100 \mu \mathrm{l}$ of each treatment were added to the wells containing a single layer of HT29 cell line. After 2 hours of incubation, the culture medium was removed from wells. Subsequently, the MTT test was performed according to the manual of the manufacturer (Pars Tus Inc., Iran). Briefly, $100 \mu 1$ of phenol red-free RPMI 1640 containing $2 \%$ fetal bovine serum and $10 \mu \mathrm{l}$ of MTT working solution 
was added to each well and the plate was incubated for 4 hours at $37^{\circ} \mathrm{C}$ in a $\mathrm{CO}_{2}$ incubator. The medium was then aspirated, and the formazan crystals were solubilized by adding $50 \mu \mathrm{l}$ of DMSO per well for 10 minutes at $37^{\circ} \mathrm{C}$ in a $\mathrm{CO}_{2}$ incubator. Finally, the intensity of the dissolved formazan crystals (purple color) was quantified using the ELISA plate reader at $570 \mathrm{~nm}$. The test was done in triplicate. cytotoxicity was calculated by the following equation (16):

Cytotoxicity $=\left(1-\frac{\text { OD sample }}{\text { OD control }}\right) \times 100$

Bacterial adhesion assay. HT-29 cells were cultured in the wells described in steps 4 and 5 in 24 wells cell culture plates (with $6 \times 10^{4}$ seeding density). After formation of monolayer cell, $125 \mu \mathrm{l}$ of each bacterial suspensions $\left(2 \times 10^{7} \mathrm{CFU} / \mathrm{ml}\right.$ in RPMI medium) (at MOI of 10) and supernatant with different concentrations were added to wells and incubated for 2 hours. Then culture medium was removed and the HT-29 cells washed three times using PBS (15). Then the epithelial cells were lysed with $0.1 \%$ (v/v) Triton X-100 (Merck, Germany) for $5 \mathrm{~min}$ at $37^{\circ} \mathrm{C}(21,22)$. In order to record the adhered viable bacteria, the suspension was cultured in the nutrient agar medium. After one day incubation, the formed colonies were transferred to MacConkey agar media by replica plating technique. To differentiate between B. coagulans and $S$. Typhimurium, colonies that were grown on the nutrient agar and MacConkey agar were considered as $S$. Typhimurium and colonies that were grown on nutrient agar but did not grow on the MacConkey agar were considered as B. coagulans. Each experiment was performed in triplicates.

Statistical analysis. Statistical analysis was performed using the SPSS software version 16 (SPSS, Inc., Chicago, IL), one-way ANOVA and Tukey post hoc tests were used. All results were shown as mean standard deviation. Differences at $\mathrm{p}<0.05$ were considered as statistically significant.

\section{RESULTS}

MIC. Results showed, $8 \%$ and $4 \%$ concentrations of supernatant ( 80000 and $40000 \mu \mathrm{g} / \mathrm{ml})$ had the highest inhibitory effect on the growth of $S$. Typhimurium (with the values of $54.77 \% \pm 1.43$ and $43.46 \% \pm 1.32$, respectively) (Fig. 1).

Cell cytotoxicity. MTT assay was used to study the effects of B. coagulans on the cytotoxicity of $S$. Typhimurium. The highest and lowest cytotoxicity was observed in the $8 \%$ and $4 \%$ concentrations with the averages of $27.86 \pm 3.09$ and $5.31 \pm 0.83$, respectively. However, only the $8 \%$ concentration showed a significant level of cytotoxicity (Fig. 2).

Concomitant culture of HT-29 cells with $S$. Typhimurium alone, together with B. coagulans or its supernatant were also performed. The highest and lowest cytotoxicity were respectively obtained for $S$. Typhimurium alone and its simultaneous culture with $B$. coagulans (with the averages of $67.61 \pm 4.51$ and $26.06 \pm 3.79$ ). In these experiments, simultane-

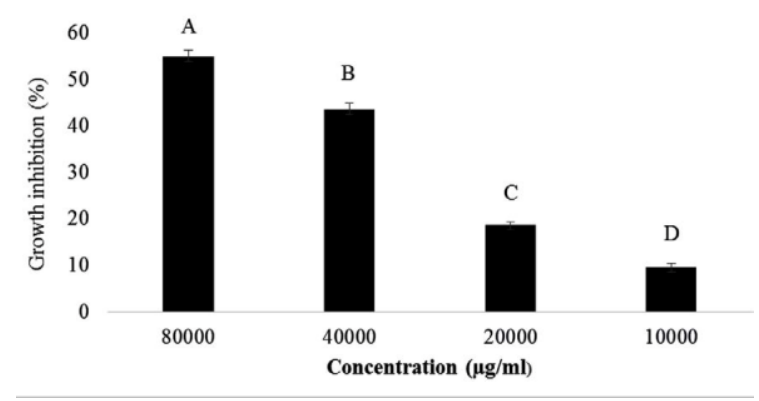

Fig. 1. Minimal inhibitory concentration of $B$. coagulans supernatant against $S$. Typhimurium. The antennas represent the standard deviation value and different Latin capital letters above the columns indicate a statistically significant difference between the columns $(\mathrm{p}<0.05)$

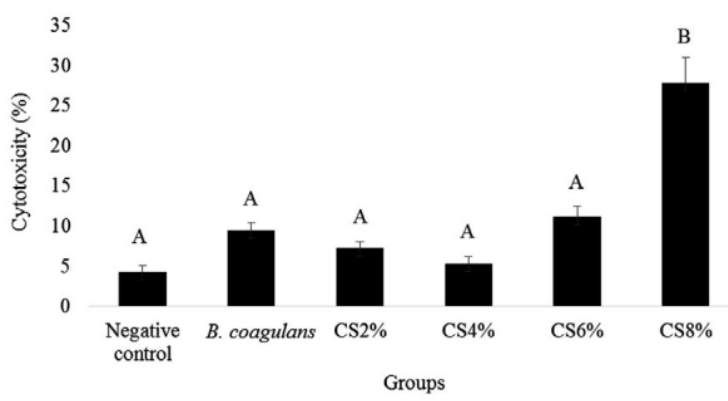

Fig. 2. Cytotoxicity of B. coagulans and its supernatant with various concentration (CS). The antennas represent the standard deviation value and different Latin capital letters above the columns indicate a statistically significant difference between the columns $(\mathrm{p}<0.05)$ 
ous culture of $S$. Typhimurium and $B$. coagulans was remarkably reduced the cell cytotoxicity caused by $S$. Typhimurium (Fig. 3).

Induction of apoptosis. Fluorescence staining using acridine orange and ethidium bromide was used to study the effects of $B$. coagulans on the induction of apoptosis in the HT-29 cells caused by $S$. Typhimurium. The results showed that $B$. coagulans and its supernatant revealed the highest and lowest amount of apoptosis induced in HT-29 cells was recorded for B. coagulans and its $8 \%$ supernatant with the averages of $6.01 \pm 0.42$ and $40.25 \pm 2.66$ (Fig. 4).

The simultaneous cultures of HT-29 cells with $S$. Typhimurium, B. coagulans or its supernatant revealed the highest and lowest percent of induction of apoptosis in S. Typhimurium with $8 \%$ supernatant and simultaneous culture of $S$. Typhimurium with B. coagulans (with the averages of $53.26 \pm 4.13$ and $17.63 \pm 2.14$ ) (Fig. 5). The results showed that B. coagulans significantly reduced the induction of apoptosis in HT-29 cultured cells induced by $S$. Typhimurium (Fig. 5).

Bacterial adhesion assay. The effect of B. coagulans and its supernatant on adhesion of $S$. Typhimurium to the HT-29 was investigated. Results showed the highest level of adhesion $(6.71 \pm 1.33 \%)$ induced by $S$. Typhimurium. B. coagulans significantly reduced the binding of $S$. Typhimurium to HT-29 cells $(2.69 \pm 0.88 \%$ ) (Fig. 6). Also, the percent of adhesion for $B$. coagulans was measured as $2.69 \pm 0.88 \%$.

\section{DISCUSSION}

Salmonellosis has caused a prominent concern in the global economy and as an important public health issue (22). Following bacterial infection, antibiotic

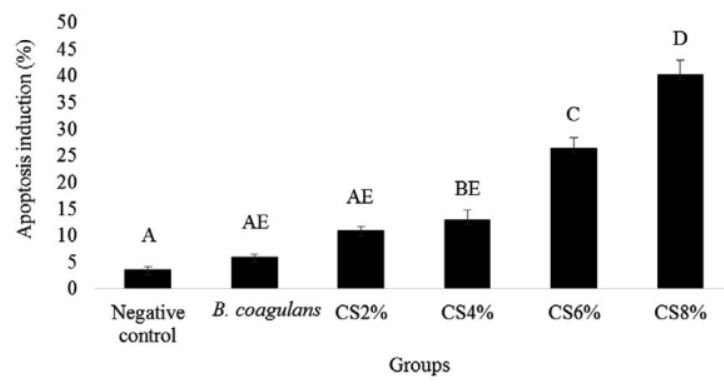

Fig. 4. Apoptosis induction caused by B. coagulans and its supernatant (CS). The antennas represent the standard deviation value and different Latin capital letters above the columns indicate a statistically significant difference between the columns $(\mathrm{p}<0.05)$

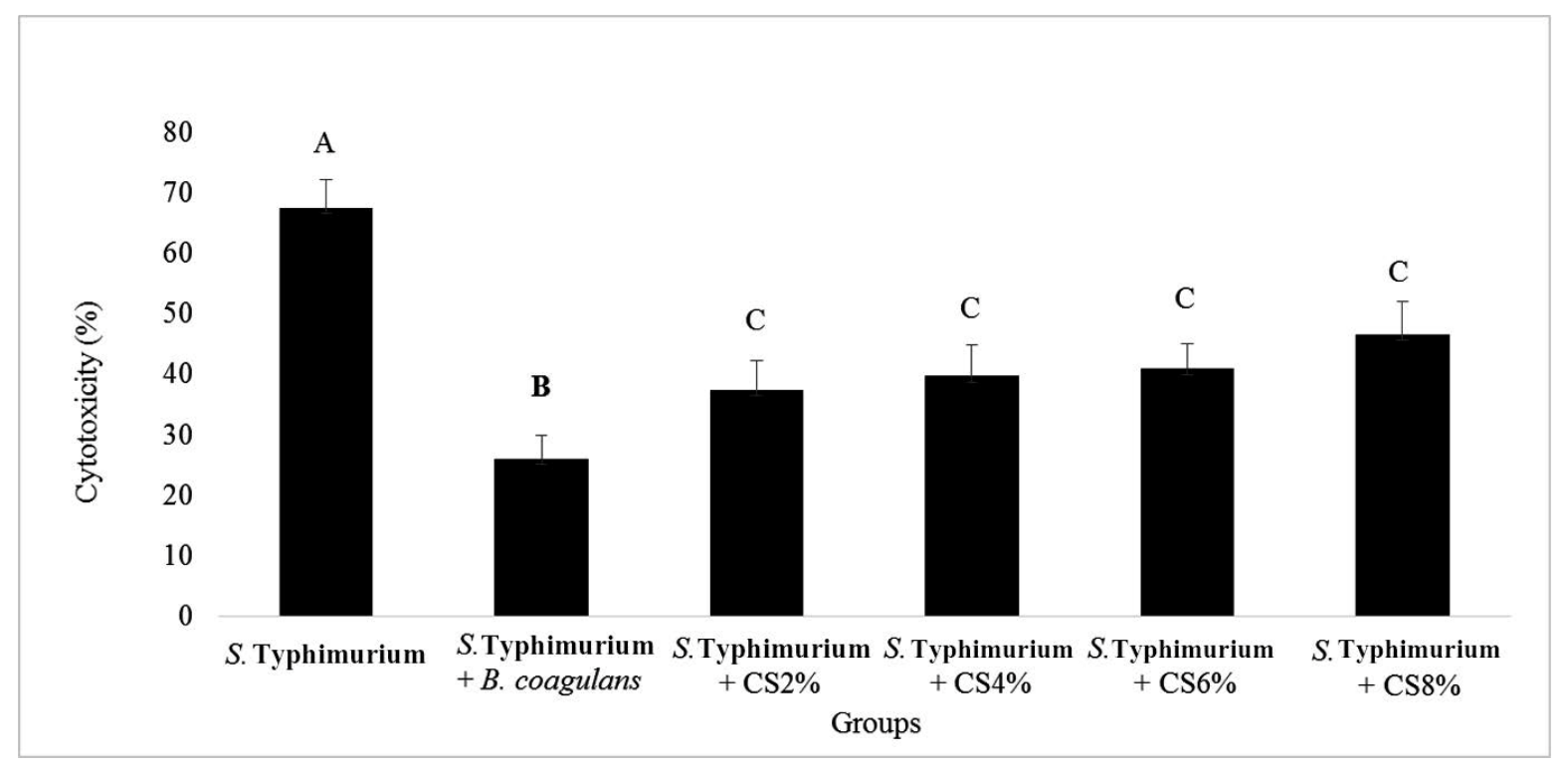

Fig. 3. Cytotoxicity of $S$. Typhimurium alone and with B. coagulans and its supernatant (CS) with various concentration. The antennas represent the standard deviation value and different Latin capital letters above the columns indicate a statistically significant difference between the columns $(\mathrm{p}<0.05)$ 


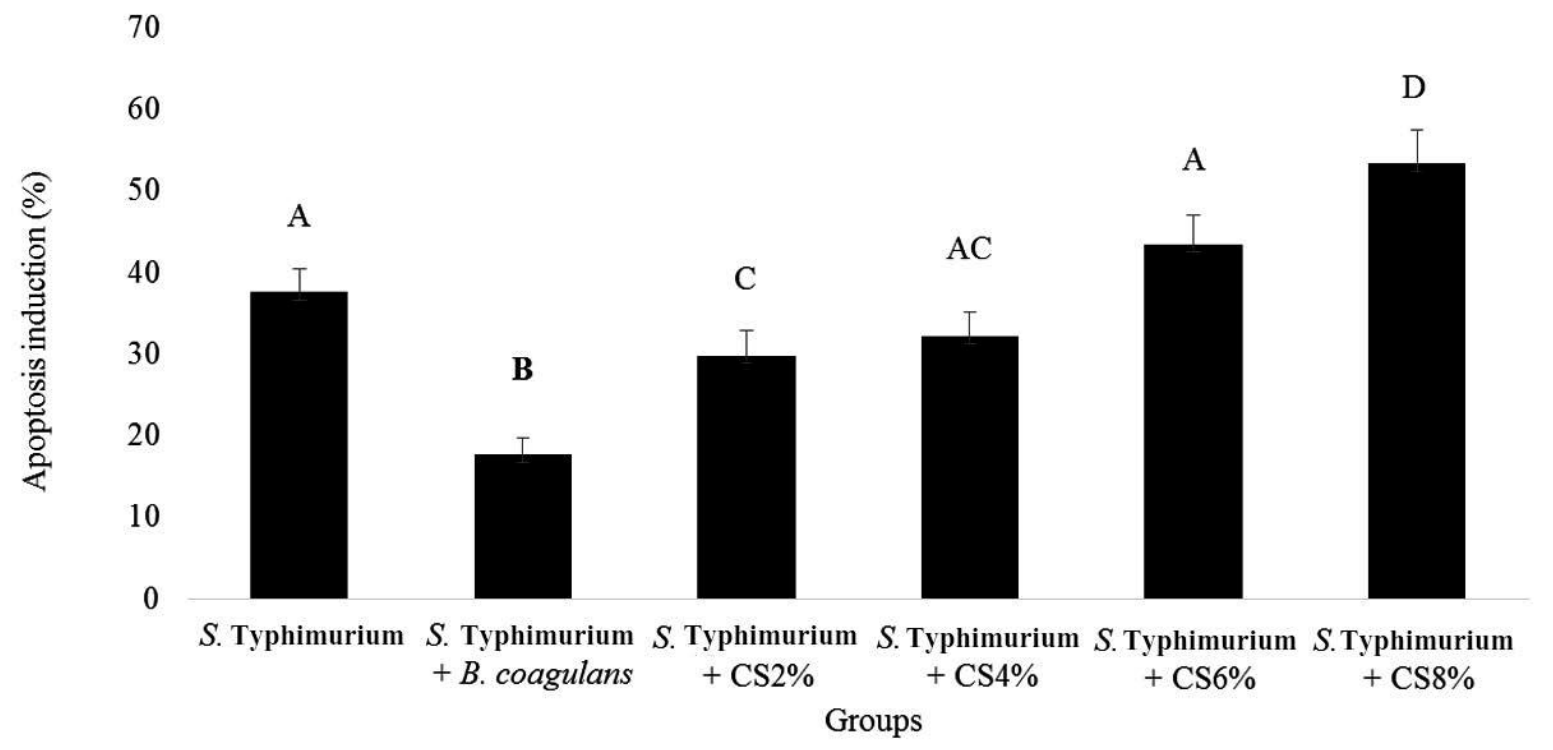

Fig. 5. Apoptosis induction caused by $S$. Typhimurium alone and with $B$. coagulans or its supernatant (CS). The antennas represent the standard deviation value and different Latin capital letters above the columns indicate a statistically significant difference between the columns $(\mathrm{p}<0.05)$

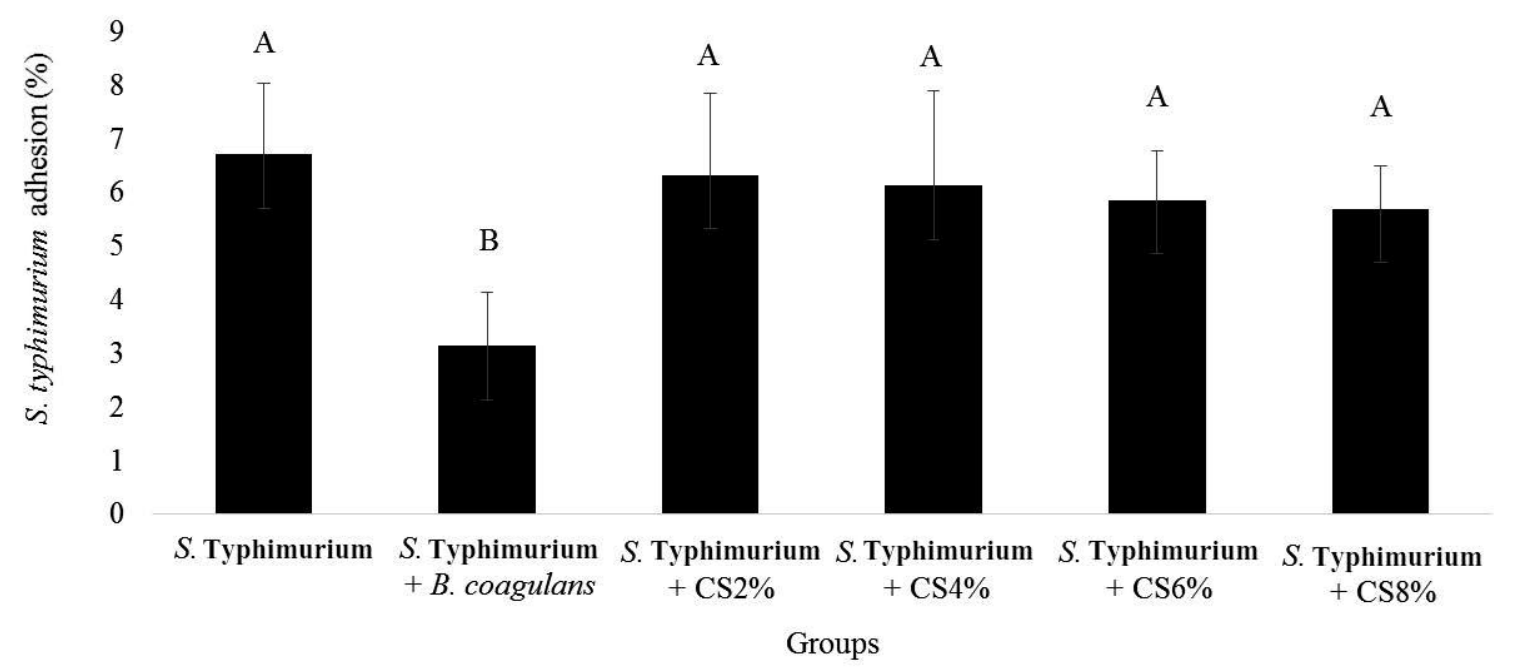

Fig. 6. Percent of $S$. Typhimurium adhesion to HT-29 cells, alone and with B. coagulans and its supernatant (CS). The antennas represent the standard deviation value and different Latin capital letters above the columns indicate a statistically significant difference between the columns $(\mathrm{p}<0.05)$

resistance is arisen and disturbing the intestinal flora balance $(12,23)$ which persuaded scientists to focus on other approaches such as probiotics and their metabolites. In vivo and in vitro studies have shown the promising effects of probiotics in the prevention and/or treatment of salmonella infections (24). The in vitro interaction between host cells and foodborne pathogenic bacteria has been previously addressed (25).

In the present study, MIC, effects of B. coagulans and its supernatant on the cell cytotoxicity, induction of apoptosis and adhesion caused by $S$. Typhimurium 
on HT-29 cells were investigated.

The beneficial effects of probiotics exhibit competitive inhibitions with the growth of pathogens such as Escherichia coli (26), Campylobacter jejuni (27), Salmonella enterica serovar Enteritidis (28) and Clostridium perfringens (29). According to previous studies, various species of probiotic bacilli can produce bacteriocins. For example, the Bacillus licheniformis bacteriocin called Bacillusin 490 that produce at $4^{\circ} \mathrm{C}$ and at a wide range of $\mathrm{pH}$ has antimicrobial activities against pathogens such as Bacillus smithii, Bacillus anthracis, Bacillus cereus and Listeria innocua (30). Previous studies have also shown that extracts obtained from probiotic $B$. subtilis and $B$. coagulans cultures showed an inhibitory effect on the Clostridium perfringens (17, 31). In the present study, the MIC of supernatant obtained from the culture of B. coagulans with concentration of $8 \%$ showed the highest inhibitory effect on the growth of $S$. Typhimurium. The results showed that by reducing the concentration of B. coagulans supernatant in each group, the inhibitory effect was also significantly decreased. This is probably due to the decrease in the concentration of the antimicrobial compounds present in the supernatant.

Higher cytotoxicity was induced by $8 \%$ supernatant of $B$. coagulans using the MTT assay. This can be due to the high concentration of toxic compounds produced by $B$. coagulans bacteria. $S$. Typhimurium showed a high level of cytotoxicity. B. coagulans was significantly reduced the cytotoxicity induced by $S$. Typhimurium. Different concentrations of $B$. coagulans supernatant did not show any significant difference in reducing the cytotoxicity induced by $S$. Typhimurium. In our previous study, the cytotoxicity of $B$. coagulans and its culture extract on NYSM medium was measured on HT-29 cells, which concluded to similar results to this study (16). The co-culture of $S$. Typhimurium and $B$. coagulans was significantly reduced the cytotoxicity compared to the supernatant. This reduction in cytotoxicity was probably associated with the production of antimicrobial and acid compounds by $B$. coagulans, which inhibit the growth of $S$. Typhimurium and prevent its adhesion to the HT-29 cells.

The results showed that the supernatant of $B$. coagulans with 8 and $6 \%$ concentrations in comparison with $B$. coagulans and its supernatant with concentrations of 2 and $4 \%$ induced apoptosis in a higher percentage on HT-29 cells. This could be due to an increase in the concentration of toxic compounds and apoptosis induced in the supernatant of this bacterium culture at the concentrations of 6 and $8 \%$.

B. coagulans supernatant at concentrations of 4 and $6 \%$ did not reduce the induction of apoptosis by $S$. Typhimurium. Simultaneous culture of $S$. Typhimurium with $B$. coagulans supernatant at $8 \%$ concentration showed a significantly higher apoptosis rate than $S$. Typhimurium.

$B$. coagulans reduced the percentage of apoptosis induced by $S$. Typhimurium more than other experimental groups. This is probably to prevent adhesion of $S$. Typhimurium to HT-29 cells. The compounds in the supernatant can inhibit the growth of $S$. Typhimurium, but cannot reduce the percentage of apoptosis induced by $S$. Typhimurium.

In this study, the adhesion of B. coagulans and $S$. Typhimurium was evaluated. In addition, the effect of $B$. coagulans and its supernatant on the adhesion of $S$. Typhimurium to HT-29 cells was investigated. The results showed that the supernatant with different concentrations did not significantly affected the adhesion of $S$. Typhimurium to HT-29 cells. But the bacterial $B$. coagulans, which also have the ability to adhesion to HT-29 cells, significantly reduced the binding of $S$. Typhimurium to this cell line. In previous studies, the binding rate of $S$. Typhimurium to epithelial cells was measured which was similar to those reported here (15).

In conclusion, $B$. coagulans probiotic and its supernatant can efficiently reduce $S$. Typhimurium injuries to the HT-29 cell line by producing antimicrobial substances. However further surveys should be conducted in vivo conditions.

\section{REFERENCES}

1. Cazorla SI, Maldonado-Galdeano C, Weill R, De Paula J, Perdigón GD. Oral administration of probiotics increases paneth cells and intestinal antimicrobial activity. Front Microbiol 2018;9:736.

2. Corthésy B, Gaskins HR, Mercenier A. Cross-talk between probiotic bacteria and the host immune system. J Nutr 2007;137(3 Suppl 2):781S-90S.

3. Servin AL. Antagonistic activities of lactobacilli and bifidobacteria against microbial pathogens. FEMS Microbiol Rev 2004;28:405-440.

4. Huttenhower C, Gevers D, Knight R, Abubucker S, Badger JH, Chinwalla AT, et al. Structure, function 
and diversity of the healthy human microbiome. Nature 2012;486:207-214.

5. Shreiner AB, Kao JY, Young VB. The gut microbiome in health and in disease. Curr Opin Gastroenterol 2015;31:69-75.

6. Nojoomi F, Ghasemian A. Effect of overgrowth or decrease in gut microbiota on health and disease. Arch Pediatr Infect Dis 2016; 4(2):e34558.

7. Bomko TV, Nosalskaya TN, Kabluchko TV, Lisnyak YV, Martynov AV. Immunotropic aspect of the Bacillus coagulans probiotic action. J Pharm Pharmacol 2017;69:1033-1040.

8. Maathuis A, Keller D, Farmer S. Survival and metabolic activity of the GanedenBC30 strain of Bacillus coagulans in a dynamic in vitro model of the stomach and small intestine. Benef Microbes 2010;1:31-36.

9. Honda H, Gibson GR, Farmer S, Keller D, McCartney AL. Use of a continuous culture fermentation system to investigate the effect of GanedenBC30 (Bacillus coagulans GBI-30, 6086) supplementation on pathogen survival in the human gut microbiota. Anaerobe 2011;17:36-42.

10. Hyronimus B, Le Marrec C, Urdaci M. Coagulin, a bacteriocin-like-inhibitory substance produced by $\mathrm{Ba}$ cillus coagulans I. J Appl Microbiol 1998;85:42-50.

11. Addis M, Sisay D. A review on major food borne bacterial illnesses. J Trop Dis 2015, 3:176-183.

12. Ghasemian A, Mobarez AM, Peerayeh SN, Abadi ATB, Khodaparast S, Nojoomi F. Report of plasmid-mediated colistin resistance in Klebsiella oxytoca from Iran. REV MED MICROBIOL 2018;29:59-63.

13. McClelland M, Sanderson KE, Spieth J, Clifton SW, Latreille P, Courtney L, et al. Complete genome sequence of Salmonella enterica serovar Typhimurium LT2. Nature 2001;413:852-856.

14. Humphrey T. Public-health aspects of Salmonella infection. Salmonella in Domestic Animals 2000;1:245263.

15. Gagnon M, Berner AZ, Chervet N, Chassard C, Lacroix C. Comparison of the Caco-2, HT-29 and the mucus-secreting HT29-MTX intestinal cell models to investigate Salmonella adhesion and invasion. J Microbiol Methods 2013;94:274-279.

16. Kawarizadeh A, Tabatabaei M, Hossinzadeh S, Poormontaseri M. Effect of Bacillus coagulans and its culture extracts on cell cytotoxicity of Clostridium perfringens type A on HT-29 cell line. Applied Microbiology in Food Industries. 2018;4(1):15-25. (In Persian)

17. Poormontaseri M, Hosseinzadeh S, Shekarforoush SS, Kalantari T. The effects of probiotic Bacillus subtilis on the cytotoxicity of Clostridium perfringens type a in Caco-2 cell culture. BMC Microbiol 2017;17(1):150.

18. Schoster A, Kokotovic B, Permin A, Pedersen P, Dal Bello F, Guardabassi L. In vitro inhibition of Clostridium difficile and Clostridium perfringens by commer- cial probiotic strains. Anaerobe 2013;20:36-41.

19. Casey J, O'Cleirigh C, Walsh P, O'Shea D. Development of a robust microtiter plate-based assay method for assessment of bioactivity. J Microbiol Methods 2004;58:327-334.

20. Behzad S, Ebrahim K, Mosaddegh M, Haeri A. Primula auriculata extracts exert cytotoxic and apoptotic effects against HT-29 human colon adenocarcinoma cells. Iran J Pharm Res 2016;15:311-322.

21. Ozkan AD, Han D, Umu OC, Angun P, Senturk B, Yasa $\mathrm{O}$, et al. Screening and selection of novel animal probiotics isolated from bovine chyme. Ann Microbiol 2013;63:1291-1300.

22. Thirabunyanon M, Thongwittaya N. Protection activity of a novel probiotic strain of Bacillus subtilis against Salmonella Enteritidis infection. Res Vet Sci 2012;93:74-81.

23. Ghasemian A, Rizi KS, Vardanjani HR, Nojoomi F. Prevalence of clinically isolated metallo-beta-lactamase-producing Pseudomonas aeruginosa, coding genes, and possible risk factors in Iran. Iran J Pathol 2018:13:1-9.

24. Castillo NA, de LeBlanc AdM, Galdeano CM, Perdigón G. Probiotics: an alternative strategy for combating salmonellosis: immune mechanisms involved. Food Res Int 2012;45:831-41.

25. Bermudez-Brito M, Plaza-Díaz J, Fontana L, Munoz-Quezada S, Gil A. In vitro cell and tissue models for studying host-microbe interactions: a review. $\mathrm{Br} \mathrm{J}$ Nutr 2013;109 Suppl 2:S27-34.

26. Golowczyc M, Mobili P, Garrote G, Abraham A, De Antoni G. Protective action of Lactobacillus kefir carrying S-layer protein against Salmonella enterica serovar Enteritidis. Int J Food Microbiol 2007;118:264-273.

27. Morishita TY, Aye PP, Harr BS, Cobb CW, Clifford JR. Evaluation of an avian-specific probiotic to reduce the colonization and shedding of Campylobacter jejuni in broilers. Avian Dis 1997:41:850-855.

28. Pascual M, Hugas M, Badiola JI, Monfort JM, Garriga M. Lactobacillus salivarius CTC2197 prevents Salmonella enteritidis colonization in chickens. Appl Environ Microbiol 1999;65:4981-4986.

29. Teo AY-L, Tan H-M. Inhibition of Clostridium perfringens by a novel strain of Bacillus subtilis isolated from the gastrointestinal tracts of healthy chickens. Appl Environ Microbiol 2005;71:4185-4190.

30. Martirani L, Varcamonti M, Naclerio G, De Felice M. Purification and partial characterization of bacillocin 490, a novel bacteriocin produced by a thermophilic strain of Bacillus licheniformis. Microb Cell Fact 2002;1:1.

31. Kawarizadeh A, Tabatabaei M, Hosseinzadeh S, Farzaneh M, Pourmontaseri M. The effects of probiotic Bacillus coagulans on the cytotoxicity and expression of alpha toxin gene of Clostridium perfringens Type A. Anaerobe 2019; 59:61-67. 